The International Journal of Multimedia \& Its Applications (IJMA) Vol.10, No.1/2/3, June 2018

\title{
Campus Virtual Tour Design To ENHANCE VISITOR EXPERIENCE AND INTERACTION IN A NATURAL ENVIRONMENT
}

\author{
Tengku Siti Meriam Tengku Wook ${ }^{1}$, Intan Yusrina Zairon ${ }^{1}$, Noraidah \\ Sahari@Ashaari ${ }^{1}$, Mushrifah Idris ${ }^{2}$, Nor Azan Mat Zin ${ }^{1}$, Hairulliza Mohamad \\ Judi $^{1}$, Norleyza Jailani ${ }^{1}$ \\ ${ }^{1}$ Research Centre for Software Technology and Management (SOFTAM), Faculty of \\ Technology and Information Science, National University of Malaysia \\ ${ }^{2}$ School of Environment \& Natural Resources Science, Faculty of Science and \\ Technology, National University of Malaysia
}

\begin{abstract}
The natural forest and natural laboratory of the UKM campus are a part of nature that could be made into attractions for tourists and visitors, as they are abundant with natural resources, including scenic views, topography, as well as water features, plants, and heritage. The university has undertaken various efforts to share this information through portals and web pages. However, the method of information delivery display and delivery of static text and graphics is not that effective. As a consequence, users or visitor are unable to interact or appreciate the experience of being in an natural environment. Therefore, this study has developed a campus virtual tour design to enhance interaction experience in natural environment through a low-fidelity interface design method, brainstorming, and virtual tour prototype development. The result of this study is a campus virtual tour design that can enhance the experience of benign, and utilisation of a natural environment.
\end{abstract}

\section{KEYWORDS}

Virtual reality, photorealistic, panoramic view, virtual tour

\section{INTRODUCTION}

The campus virtual tour is a popular approach to control construction in the university campus environment-whether locally or abroad-to improve the visibility and presence of user experienceand ensure sustainability in delivering campus environmental messages to educate staff, students, and visitors[1]. The campus virtual tour can be implemented formally, informally, and in an informal capacity to reach a wider scope of campus residents [2]. Understanding of campus virtual tour in environmental education refers to the process of shaping the user to recognize values and clarify concepts for building skills and attitudes towards the environment.This allows the user to understand the relationship between humans, culture, and the natural environment. Users thus obtainthe skills to make decisions and the ability to summarize actions based on their belief of said environment $[3,4,5]$.

The university campus is a unique environment consisting of an individual community, as it can learn from, and globally connect societies. The unique nature of the university campus and completemastery of the campus environment can create subject specialization in environmental and developmental educationstudies. Ecotourism studies have revealed the benefits of formal and DOI: 10.5121/ijma.2018.10307 
The International Journal of Multimedia \& Its Applications (IJMA) Vol.10, No.1/2/3, June 2018

informal education through individual interpretation [6,7].Based on the findings in [6], education pertaining to places visited can impact and build relationships as well as provide experiences and fulfill visitor wants. Besides that, environmental education also has the potential to change the attitude of visitors through not only being merely an attraction, but also by leaving an impact on visitorseven after they have left[7].

The design of the campus virtual tour, which includes videos consisting of a combination of images and audio, provide numerous benefits for demo and instructional functions. This is because the student or user tends to better remember information acquired from videos rather thanthrough reading or listening [8]. The development of a campus virtual tour is based on the Social Constructionism Theory[9], which enables the student to construct an environment and an understanding together with friends through virtual communication, besides creating a more dynamic and flexible environment[10].

There is a difference in implementing the approach for a campus virtual tour; the first approach consistsonly of an online map that shows specific locations. The second approach does not use a direct map but instead provides information-rich content via webpage.Meanwhile, the third approach shows an interactive map with video, audio, pictures, or other content when theuser selects the map filter. The fourth approach provides a set path for users interested in following its suggestion. The fifth approach uses a GIS (Geographic Information System) platform, although a different platform than GIS is almost always used[11].

The above approaches for a campus virtual tour are based on the implementation of virtual reality technology. Virtual reality is the user experience of being in the system control when browsing a virtual environment[12]. This technology also enables the user to feel as if he or she is actually in the real world while navigating the system, particularlywhen they succeed at controlling and interacting with the object and environment [13]. Virtual reality is divided into two main categories: immersive and non-immersive.

Immersive virtual reality is the direct experience of being in a virtual environment.It uses sophisticated 3D hardware technology such as the cave display system, head mounting device (HMD), glove data, and dome.Via this technology, the user is given the chance to feel the experience of being in a real environment and is in a better position to make decisions regarding their itinerary[14]. However, real-world views especially natural landscapes containing numerous display details have resulted in a complex asset development process. This technology thus incurs high cost and has limited use.

Non-immersive virtual reality is a display system that is based on multimedia presentation in a 3D environment, which relies on inexpensive and simple input devices such as the mouse, keyboard, and touch screen. The virtual environment is developed using a set of combined images that is created through a stitching process [15]. This technique enables the user to walk through and view the environment and objects in a 360-degree environment.Other techniques that can be employed are:

\section{- Tour Into Picture}

This technique creates a unique view from drawings. It enables the user or viewer to "tour into" the viewsin an image. This technique is developed through providing an intuitive and easy interface for developing a box-shaped model consisting of five rectangles, to create a background image view [16].

The foreground object at the place of occurrence is modelled as a 'billboard' polygon with each being attached to at least one other rectangular background. Besides that, the technique can also 
The International Journal of Multimedia \& Its Applications (IJMA) Vol.10, No.1/2/3, June 2018

be used to develop a panoramic image. This method can be used to create 3D animation effects that are larger compared to those created via the panning and fixed-point zoom techniques[17]. Nevertheless, this method also has some weaknesses in terms of virtual camera movement. The virtual camera movement for this method is limited to a single box. Therefore, animations that are developed tend to be shorter than conventional ones. Multispective Tour into Picture (TIP) allows the user to move his or her view into the local model to create a fly-through animation with an increasedfeeling of immersiveness.

\section{- Concentric Mosaic/Image Mosaic[15, 18]}

The mosaic technique is constructed via a few stitched images with each image being suited to different sceneries recorded from the same view.This method is based on using a conventional imaging lenses to capture the image sequence. There are two types of mosaics that can be developed i.e. concentric mosaic and imagemosaic.

A concentric mosaic can be constructed using image block arrangement taken from different locations for each cycle.Camera movementis constrained throughout a concentric circle on a plane.A concentric mosaic indexes all image ray inputs naturally based on three parameters i.e. radius, angle of rotation, and vertical elevation. A novel view is displayed viaeffectively combining the appropriate image ray during the exposure session. Concentric mosaics can be developed for real scenes in 10 minutes by rotating a cameracentred on a turntable. Even though this method does not require the modelling of difficult geometric and photometric models of scenes, it still provides a better user experience through allowing the user to move around freely and observe the apparent changes in parallax and lighting.

On the other hand, panoramic mosaics can be developed from just a few normal images. If the focal length of a camera is known and fixed, the developer could project the image onto a cylindrical map so that the relationship between the cylindrical imagesbecomes simpler and easier to translate. For example, to achieve camera rotation, the image must first be registered by renewing the camera movement before converting it to the final cylindrical or spherical map. The steps to create a panoramic view via mosaic are as follows:

a) Node selection: A node is selected to maintain visual consistency when moving from one point to the other. The camera is fixed and must be centred on the node point. Each image must overlap with the starting point. The stitching process: The objective of this process is to create a suitable panoramic image from the overlapping images.

b) Tagging the hotspot location: This process is done to identify the area on the panoramic image for interaction purposes.

c) Connecting the panoramic view: A link, which the user can activate, is placed on the hotspot.

d) Image compression: the size of the panoramic image is changed to an optimal size for presentation on thesystem.

Hence, the objective of this study is to investigate an effective interaction design to develop a campus virtual tour web application that allows the user to enjoy and appreciate the experience of being in a natural environment through the implementation of non-immersive technology. Via the virtual tour simulation approach, visitors caninteractively select tour paths and views, thus encouraging their desire to visit the real location, which will in turn attract more tourists. This technique is more attractive compared to traditional tourism publicity that only uses videos or stillimages [16]. 
The International Journal of Multimedia \& Its Applications (IJMA) Vol.10, No.1/2/3, June 2018

\section{BACKGROUND OF STUDY}

This study focuses on Tasik Chini Research Centre (TCRC), Universiti Kebangsaan Malaysia (UKM), as the campus virtual tour case study. UKM has the potential to become an ecotourism destination because of its numerous outstandingnatural and heritage advantage such as its campus natural forest and natural laboratory.This advantage is unlike any other university in Malaysia. However, UKM is not known among the local or international community for this advantage because of its information display via portal, whichtakes the form of static text and graphics with no interaction. Overseas universities have accelerated far ahead with each introducing their own advantages via online access and application of walk-through and exploration of 360-degree virtual environments using desktop computing and mobile devicescreens[2]. The objective of the exploration concept is to display information and allow the user to feel as if he or she is actually in the real environment, which can increase effectiveness and usability. Currently, there are more than 100 universities locally and abroad that have applied the virtual exploration concept in introducing their institution all over the world, via immersive and non-immersive technology.

In line with the above, this study has conducted an analysis of campus virtual tours of 20 local and international universities, including a user requirement analysis

\subsection{ANALYSIS}

This analysis involves 10 overseas universities such as Newcastle University, Harvard College, University of Exeter, Loughborough University, University of Sussex, Brunel University London, Herriot Watt University- Edinburgh Campus, East Stroudsburg University, University of Adelaide, and The University of Auckland. The 10 local universities are IMU International Medical, Universiti Malaysia Terengganu, INTI International University, Universiti Malaysia Kelantan, Universiti Teknologi Malaysia, Nilai University, Universiti Malaysia Sarawak, KDU Penang University College, Limkokwing University of Creative Technology, and Taylor's University. The aim of this analysis is to observe the currenttrends in information display.

A user requirement analysis was conducted using the interview method with five staff from Tasik Chini Research Centre (TCRC).The aim of this analysis is to extract the respondents' views of the types of information display and information categorization methods in a system.

\subsection{ReSUlts Of The ANALYSIS}

The findings of the analysis involving 20 overseas and local universities show that all the universities have applied the walkthrough and exploration concept in a virtual $360^{\circ}$ environment, in an effort to prioritize the user interaction context towards diverse dimensionswith emphasis on effectiveness and usability aspects. The information display technique used is panoramic virtual reality that allows the visitor to enjoy and appreciate the experience of being in an environment via the implementation of non-immersive technology.

The results of the analysis of user requirements are outlined in Table 1

Table 1 The Results of the Interview

\begin{tabular}{|c|c|c|}
\hline Theme & Main Category & Subcategory \\
\hline & & Flora Fauna \\
The function of & Research & Climatology \\
TCRC & Hydrology \\
& & Water quality \\
& Community \\
\hline
\end{tabular}


The International Journal of Multimedia \& Its Applications (IJMA) Vol.10, No.1/2/3, June 2018

\begin{tabular}{|c|c|c|}
\hline & & $\begin{array}{c}\text { Engineering } \\
\text { Architecture } \\
\text { Information Technology (IT) }\end{array}$ \\
\hline & Edu-tourism & $\begin{array}{c}\text { Research } \\
\text { Tours } \\
\text { Awareness program and Orang Asli } \\
\text { community }\end{array}$ \\
\hline & Tourism activity & $\begin{array}{c}\text { Kayaking } \\
\text { Fishing } \\
\text { Camping } \\
\text { Jungle trekking }\end{array}$ \\
\hline & Graphical display & $\begin{array}{c}\text { Simple but with complete information } \\
\text { Attractive } \\
\text { Education-based design }\end{array}$ \\
\hline & Menu display & Easy to find and not complicated \\
\hline & Navigation & Easy to access and use \\
\hline Information & Plan & Hotspot and location plan \\
\hline display features & Interaction & $\begin{array}{c}\text { Two-way interaction } \\
\text { Cursor } \\
\text { Controller } \\
\end{array}$ \\
\hline & Compatibility & $\begin{array}{c}\text { Desktop } \\
\text { Mobile device }\end{array}$ \\
\hline & Help & $\begin{array}{l}\text { Audio (3 languages) } \\
\text { Tour Guide Avatar } \\
\text { " } i \text { 'link for info }\end{array}$ \\
\hline
\end{tabular}

Based on Table 1, the function of the TCRC establishment is to expand upon research and knowledge sharing for the Tasik Chini Biosphere Reserve area. There are 7 core research areas in TCRC, which are flora and fauna, climatology, hydrology, water quality, community, engineering, architecture, and information technology. Besides that, TCRC is open to the public including schools or universities that wish toconduct tour activities, research, community program with the Orang Asli or awareness program. The public can book through official correspondence or direct application with TCRC. Among the activities that can be done in Tasik Chini are water activities such as kayaking and fishing, as well as visiting the Orang Asli village. In addition, camping sites are also provided for visitors that want to camp in the area. TCRC also provides a boat rental service and tourguides in the event that the tourists would like to go boating on the lakeor jungle trekking.

The results of the analysis of campus virtual toursof 20 local and overseas universities and the user requirement analysis point toward information display features that can be implemented in the design of the campus virtual tour in this study;thuspreventing the problem of cognitive load and navigate onthat often occurs in existing virtual tour systems. Cognitive load refers to the total mental activity of working memory at any one time [19].Each interface design must be designed to consider the requirements, cognitive ability, and limitations of the user [20]. A wholistic, simple, and attractive graphical display will facilitate the user when browsing througha virtual tour portal. Location and position of the menu link and clear and consistent buttons would make it easier for the user to identify each menu function [21]. The slide or hidden navigation type could enhance user experience, as they would be able to view and browse the virtual tour portal without any interference from the display [22]. The use of a map or floorplan could prevent the user from getting lost in the application or system. The user could also access other information by just using the hotspot point on the map. 
Besides that, the cursor can be used as a compass to facilitate the user when searching for the actual path to walk through the virtual tour.To enable ease of access anywhere, it would be better if the system were displayed not only on desktops but also on mobile devices. The final information display feature is the help feature. All interview respondents agreed on the use of a tour guide avatar and audio help, which would make for a more attractive and fun information delivery.

In line with the above, non-immersive technology via a hybrid approach was implemented in the design of the campus virtual tourin this study. This approach uses an interactive map as a feature, which contains video, audio, andpictures.It also provides rich information content, which can be accessed from a webpage. On the other hand, the information display technique used in this study is the Concentric Mosaicing technique. Figure 1 shows the conceptual model that was developed to meet the requirements and wants of the user, as identified in the analysis phase.

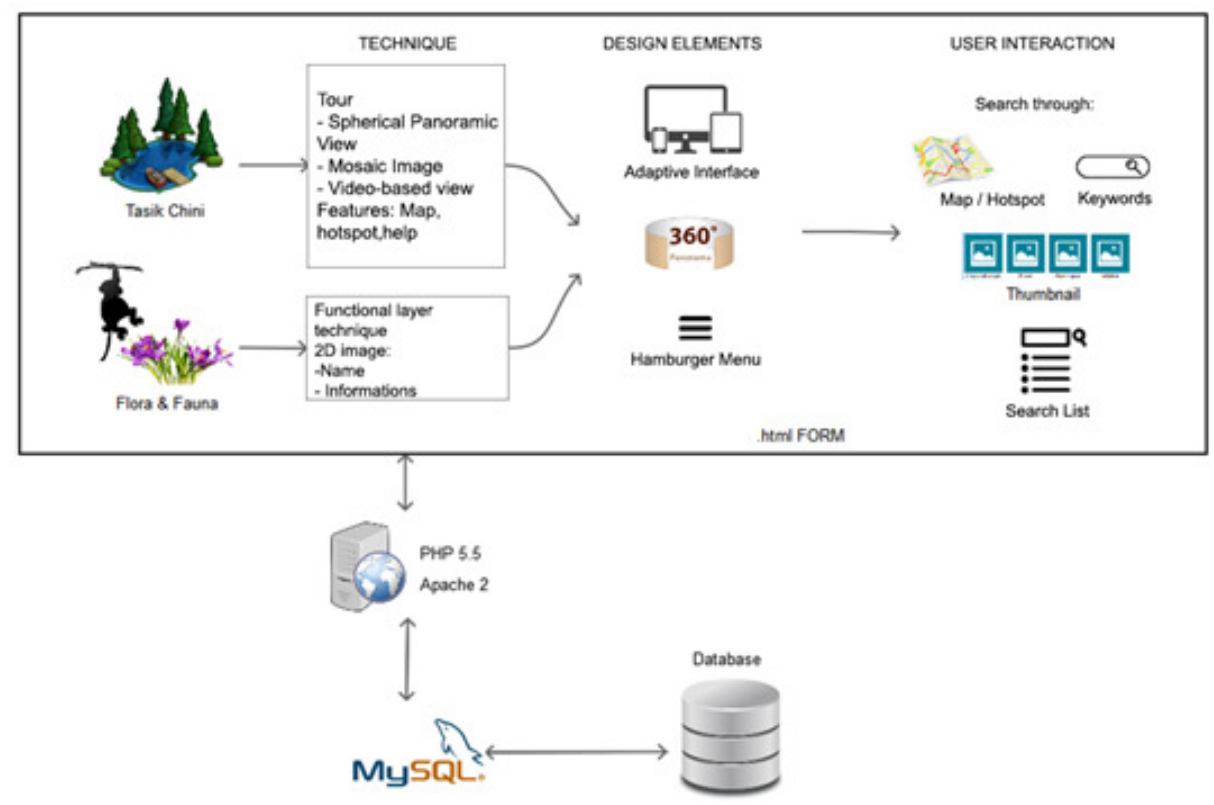

Figure 1 Tasik Chini Virtual Tour Conceptual Model

Figure 1 shows the different techniques used to present the virtual tour of Tasik Chini as well as its flora and fauna information.For the Tasik Chini virtual tour, the panoramic view exploration technique based on image mosaicingis used. The features of the virtual tourdisplay include a map, hotspot, and help. Meanwhile, the functional layer technique is used to display 2D images and the flora and fauna information. An adaptive interface design element and hamburger menu were chosen in the development of the virtual tour portal to reduce cognitive load and overflow of information. The selection and usage of the information presentation technique based on panoramic view aims to provide the real experience for users besides reducing the use of mobile devices.

The user will be able to interact with the system through the hotpost or map features to seach for attractive locations in Tasik Chini. In addition, the user would also be able to search for information regarding flora and fauna through list-based searching implemented on the display menu. 
The International Journal of Multimedia \& Its Applications (IJMA) Vol.10, No.1/2/3, June 2018

\section{Campus Virtual Tour Design}

Papers in this format must not exceed twenty (20) pages in length. Papers should be submitted to the secretary AIRCC.Papers for initial consideration may be submitted in either .doc or .pdf format. Final, camera-ready versions should take into account referees' suggested amendments.

\subsection{LOW-FIDELITY INTERFACE DESIGN}

This phase entails the construction of the interface design for exploration of the virtual tour web application, which fulfills the user interaction contextof the different requirements anddiversedimensiondesign.In this phase, a system flowchart and sketch of a low-fidelity interface based on the findings of campus virtual tour and user requirements is constructed. Figure 2 shows the flowchart detailing the developed system design. Meanwhile, Figure 3 until Figure 6 present the low-fidelity interface design sketch of the campus virtual tour application on the homepage of the portal as well as information display features in line with user requirements.

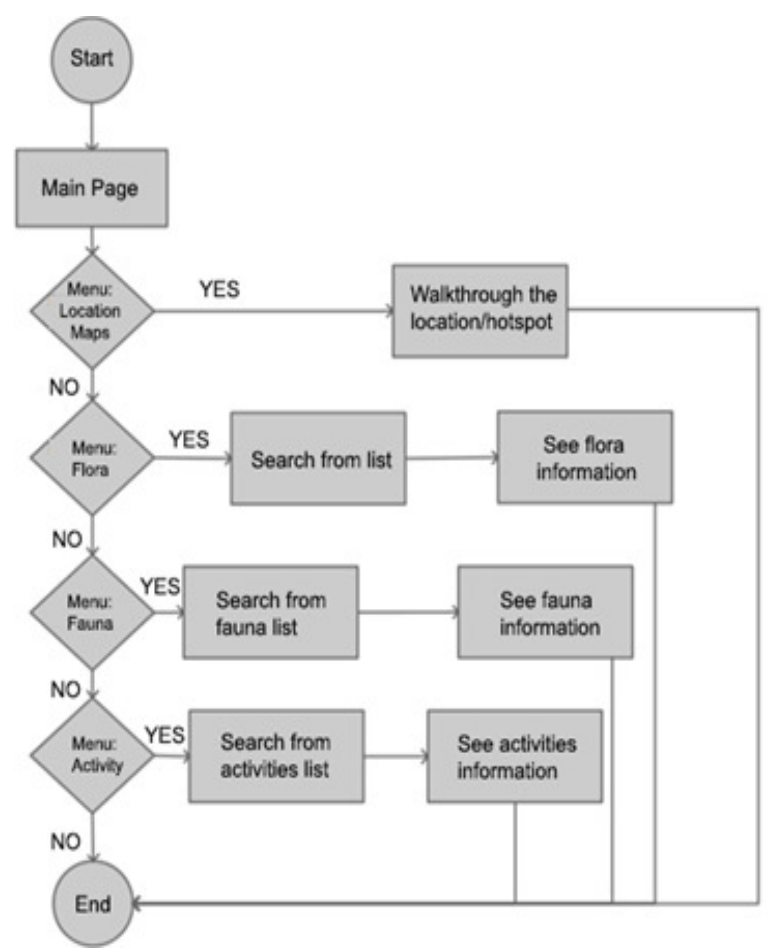

Figure 2 Virtual campus Flow Chart 
The International Journal of Multimedia \& Its Applications (IJMA) Vol.10, No.1/2/3, June 2018

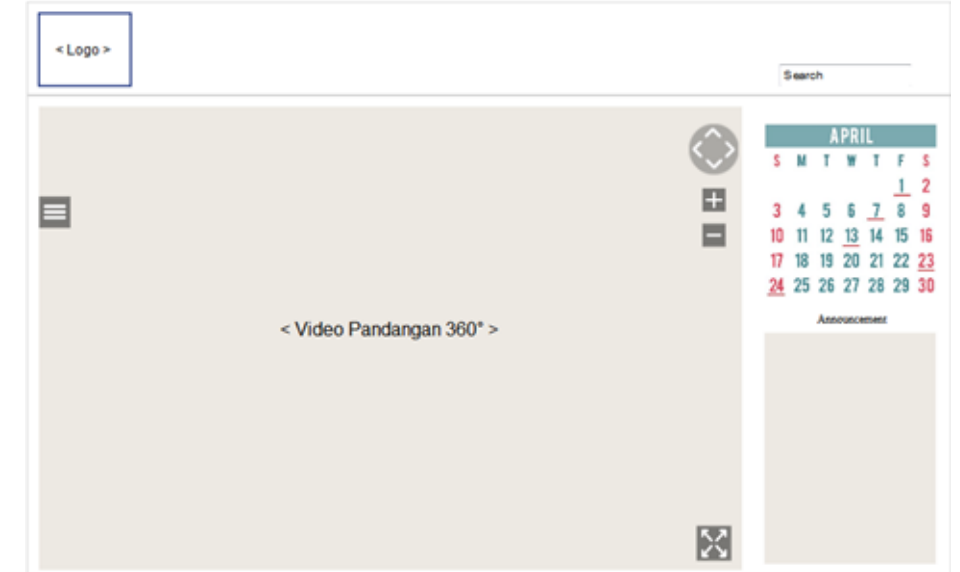

Figure 3 Main Page Interface

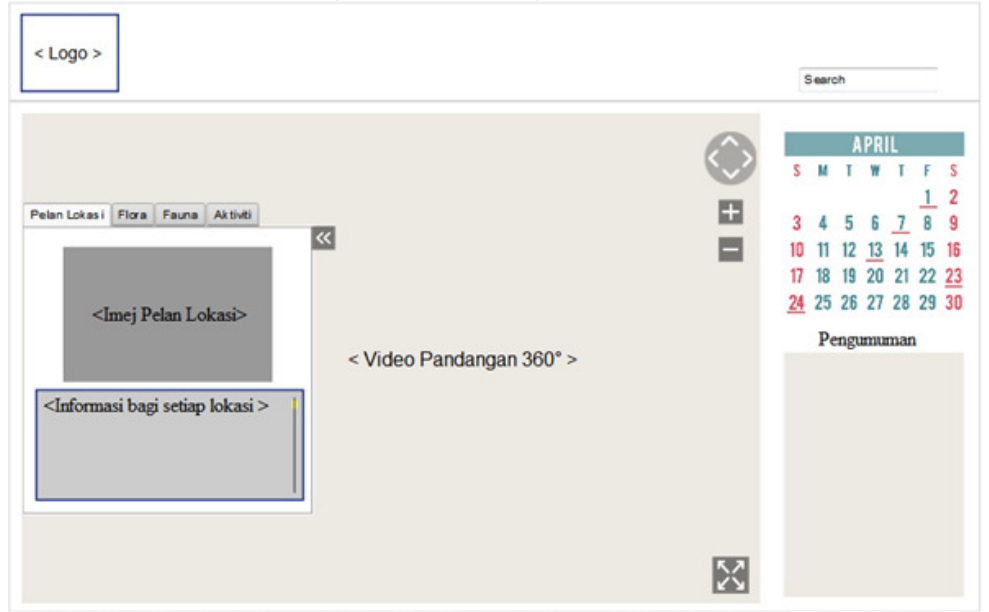

Figure 4 Location Maps Interface

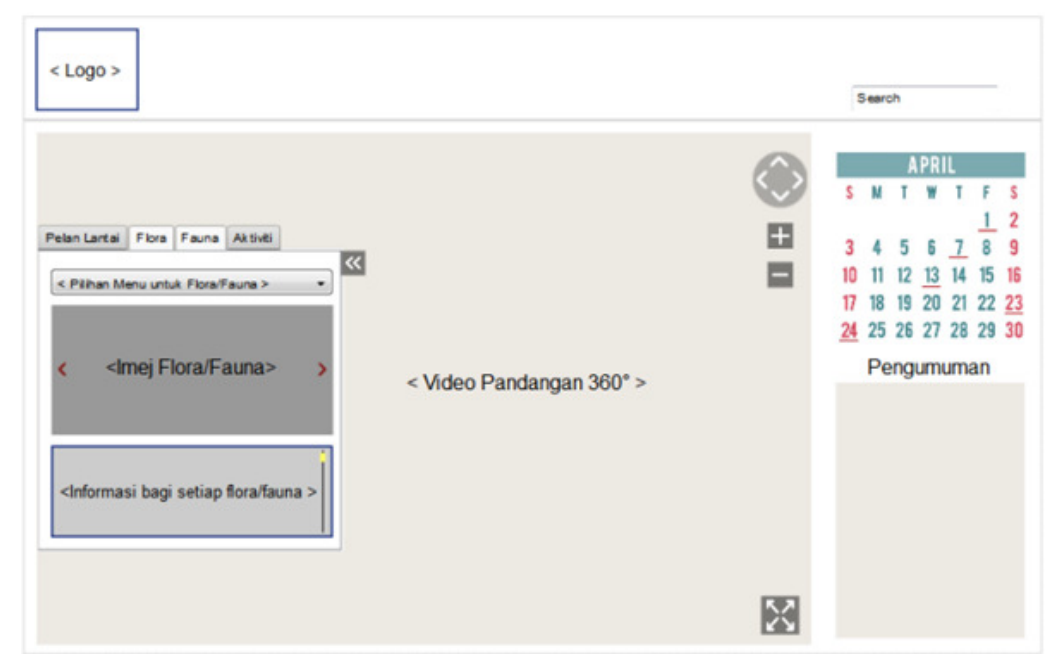

Figure 5 Flora/Fauna Interface 
The International Journal of Multimedia \& Its Applications (IJMA) Vol.10, No.1/2/3, June 2018

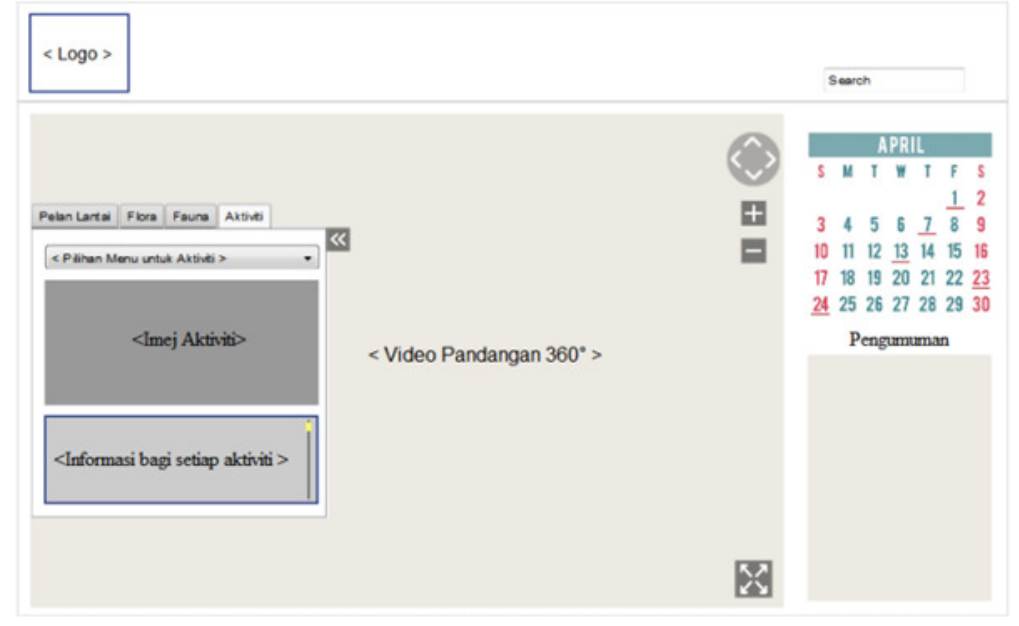

Figure 6 Activities Interface

\subsection{BRAINSTORMING}

The second phase consists of conducting the brainstorming method with eight researchers from the Faculty of Technology and Information Science (FTIS) and Faculty of Science and Technology (FST). The objective of this method is to analyze the researchers' perspective of information display features.

The procedure consists of the distribution of a set of questionnaires to the researchers, which requires them to visit 10 sample virtual tours locally and overseas. The results of the analysis based on this questionnaire are outlined in Table 2 below:

Table 2. Researcher Brainstorming

\begin{tabular}{|l|l|l|}
\hline Theme & Main Category & Subcategory \\
\hline \multirow{4}{*}{$\begin{array}{l}\text { Information display } \\
\text { features }\end{array}$} & Graphical display & $\begin{array}{l}\text { Simple but information is complete } \\
\text { Attractive } \\
\text { Educational-based design }\end{array}$ \\
\cline { 2 - 3 } & Menu display & Easy to find and is not complicated \\
\cline { 2 - 3 } & Navigation & Easy to access and use \\
\cline { 2 - 3 } & Plan & Hotspot and location plan \\
\cline { 2 - 3 } & Interaction & $\begin{array}{l}\text { Two-way interaction } \\
\text { Cursor } \\
\text { Controller }\end{array}$ \\
\cline { 2 - 3 } & Compatibility & $\begin{array}{l}\text { Desktop } \\
\text { Mobile device }\end{array}$ \\
\cline { 2 - 3 } & Help & $\begin{array}{l}\text { Audio (3 languages) } \\
\text { Tour Guide Avatar } \\
\text { "i” link for information }\end{array}$ \\
\hline
\end{tabular}

Based on Table 2, seven main featuresfor information display are discussed, which are graphical display, menu display, navigation, plan, interaction, compatibility, and the help function. For graphical display, the majority of the researchers opined that the display should be simple, attractive, and educational-based. However, the simple graphics must also include complete information. Besides that, the menu display must also be easy to find, and the navigation easy to 
The International Journal of Multimedia \& Its Applications (IJMA) Vol.10, No.1/2/3, June 2018

use and not complicated to facilitate first-time users of the virtual tour application. The hotspot and location plan can enhance the interaction level with the user besides preventing the user from becoming lost during the visit. In addition, the researchers also suggested that the virtual tour be displayed on both desktop and mobile device. With this, the user would be able to access the virtual tour application wherever they may be. Finally, in terms of the help function, the use of audio and avatar was also suggested to assist users during their visit.

Each comment, suggestion, and idea given by the researchers were recorded and used as a guide to improve the interface design of the Tasik Chini virtual tour portal in this study.

\subsection{Prototype DeVelopment}

The final phase of this study is the prototype development, which is based on the feedback and ideas of the researchersobtained in the second phase. The activities in this phase arethe photo shoot and image stitching for developing the Tasik Chini virtual tour portal,which uses HTML programming language. Two photographers were involved in the photoshoot, which was done around Tasik Chini, Pahang, and using a DSLR camera and DJI Phantom III drone.The photoshoot took two days to cover the entire area of Tasik Chini including the Orang Asli village and river encircling the lake. The employed technique to create the environmental component is the inside view technique. Its concept works with the photographer having to stand in the centre, and viewing and recording the display at no less than 360 degrees.

The recorded images are stitched using EasyPano and TourWeaver software. The image stitching process is also known as a process that combines small field of view (FOW) image groupings to create a panoramic view with a bigger FOV [23]. A bigger FOV is required in the image stitching process to create a more real-time virtual tour, whilst simultaneously enabling the user to feel as if he or she is actually in the real environment.

The stitched images are inserted into the HTML programme to develop the portal. For the first version of the prototype, two homepages are provided, which are the TCRC homepage containing the Tasik Chini virtual tour and the activity calendar for Tasik Chini. For information searching, the list-basedsearch technique is provided in the menu box. The hotspots for location and fun activities are designed in the form of a pin, which the users can click on. Figure 7 shows the Tasik Chini homepage that contains a link to the virtual tour application.Figure 8 presents the virtual tour homepage interface. This page contains the virtual tour application and activity calendar. Next is the design of the information display menu, which contains 3 choices:location plan, flora, and fauna. On the location plan display menu, the user can choose the location to visit based on the hotspot pin provided on the location plan. To search for flora and fauna information, the user can search for the flora and fauna species from the menu list to determine further information about a species. This is shown in Figures 9 and 10. 
The International Journal of Multimedia \& Its Applications (IJMA) Vol.10, No.1/2/3, June 2018 $5=$

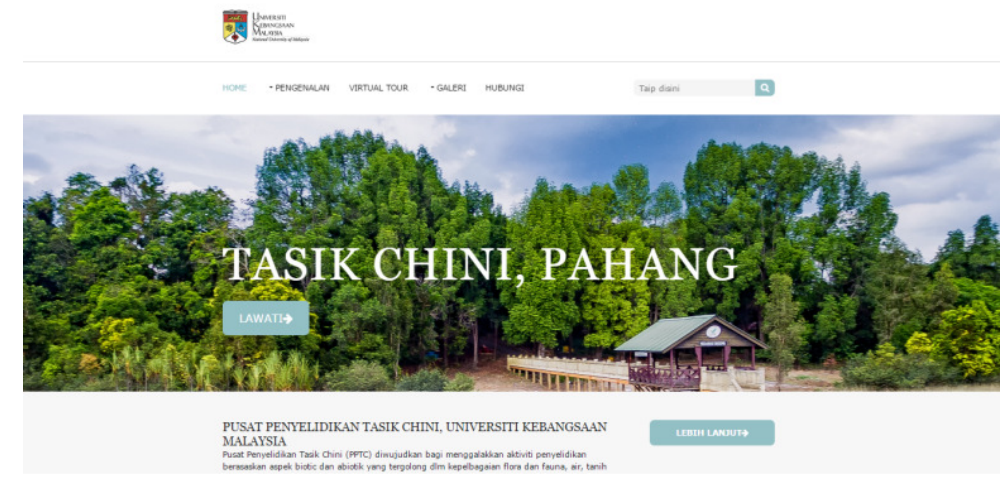

Figure 7 Main Page of Tasik Chini Research Centre

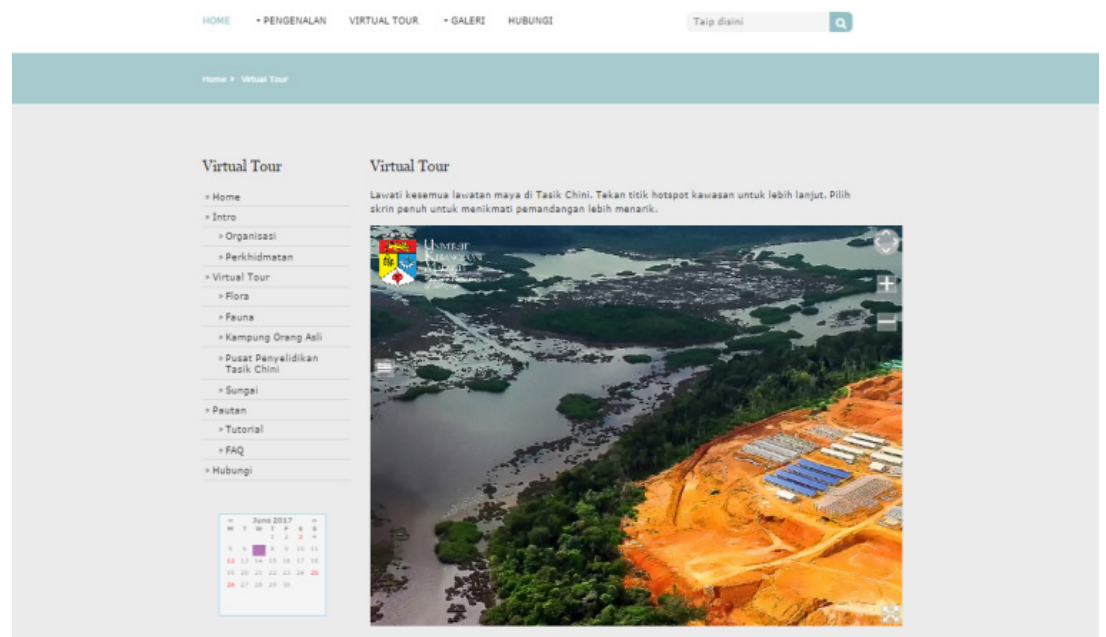

Figure 8 Main Page of Virtual Tour

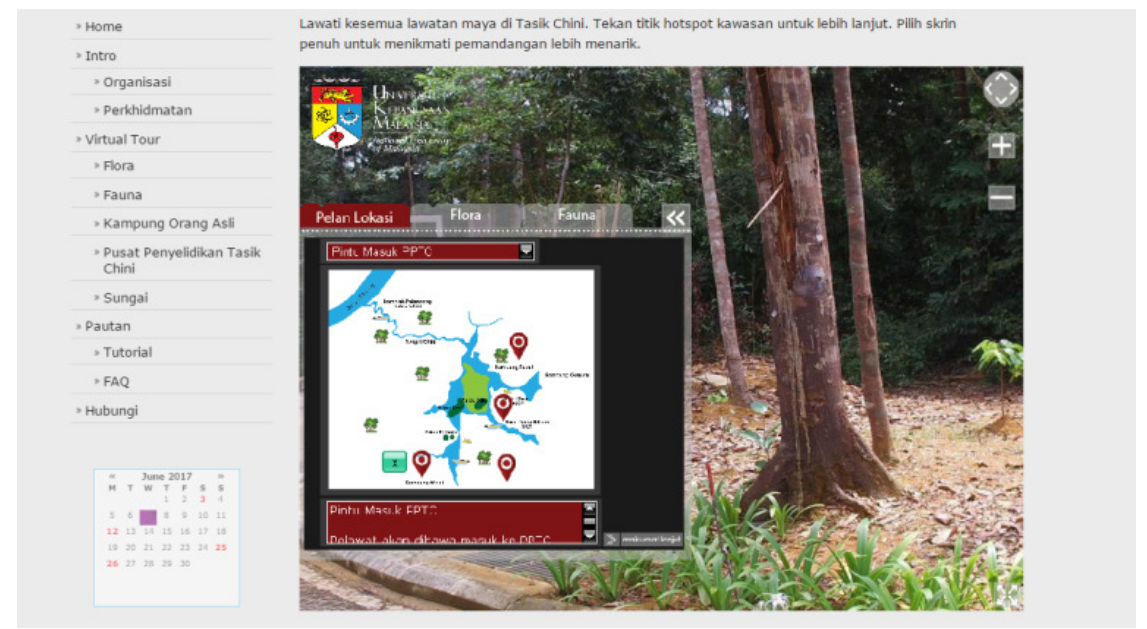

Figure 9 Tasik Chini Virtual Tour (Display Menu) 
The International Journal of Multimedia \& Its Applications (IJMA) Vol.10, No.1/2/3, June 2018

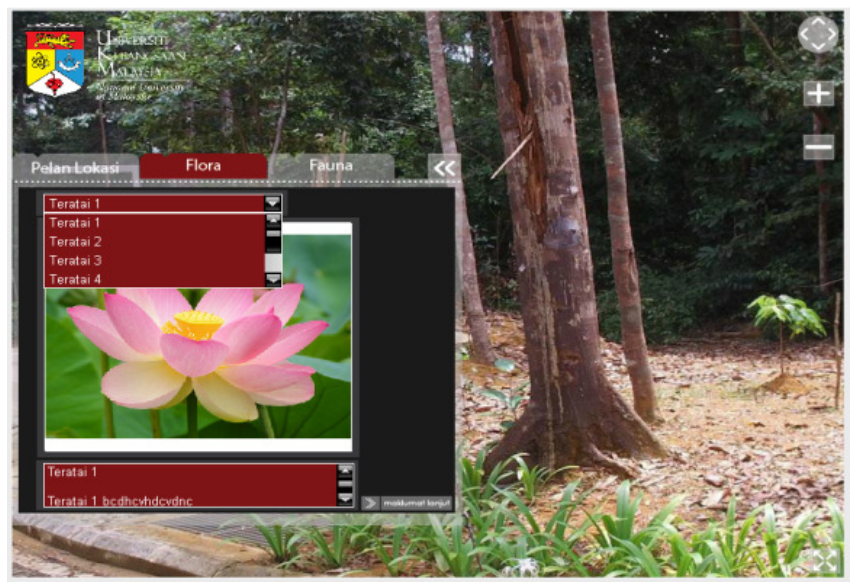

Figure 10 Tasik Chini Virtual Tour (Searching Information)

\subsection{DISCUSSION}

Multimedia content has the potential to create a huge impact on user emotions, and the sense of presence and participationin using the providedservice, application, and/or information [24]. According to Viana et al. (2016), a new paradigm for production, distribution, and media users has emerged with the introduction of different sensory modalities and audio-visual effects, which could enhance the sense of presence, enabling participation, and social interaction in media networks, while at the same time improving sense of belonging and contributing to the success of the serviceprovided.

The researcher has chosen to apply the image-based visualisation approach in developing the campus virtual tour for this study to achieve the best results of user experience. Image-based visualisation is a popular approach in the development of virtual tour applications due to its high quality photorealism factor and moderation in rendering[25]. On the other hand, the image mosaic technique is used to create the panoramic images for the virtual tour in this study. This technique focuses on the initial use of remote sensing and photography. The method is more widely used in the field of photography, virtual reality, and video and image processing, and is very highly valued [26]. Panoramic images created from the method of stitching image collections with overlapping views can provide more effective information besides improving photo resolution as well as compressing information storage capacity [27].

The image stitching technique can be categorised into two approaches, which are the Direct Approach and the Feature-based Approach. The Direct Approach uses all image pixels to be stitched as well as more correlation functions, which are expensive and complex in which each pixel is compared to other pixels. Consequently, this approach is not widely used because it is not that flexible and is influenced by the same difference in object exposure in different images during the stitching process $[28,29]$. In addition, the direct stitching technique requires more initialisation or human interaction to ensure the stitching is done correctly. This initialisation includes but is not limited to the rotation (orientation)of the image to be stitched. In contrast to the Direct Approach, the Feature-based Approach is a better method, but depends on a technique based on real features, which causes an apparent difference in stitching probability time [29]. Once the feature detector receives an image, it will start the analysis process to extract metadata from the image. This information includes how the points in the image are related to each other and other geometric relationships from the pixels in the image, which form the features extracted by the feature detector. Popular feature detectors include the Invariant Feature Transform (SIFT), Speeded Up Robust Features (SURF), and Pyramidal Histogram of Visual Words (PHOW). 
The International Journal of Multimedia \& Its Applications (IJMA) Vol.10, No.1/2/3, June 2018

The advantage of using the image-based visualisation approach is that of rendering. Since image rendering is usually done offline, the rendering speed in an application is faster compared to when a polygon model is used[30].The human eye is accustomed to detecting details of the pictured natural environment; therefore, a more complex image is provided to enhance photorealism level and natural appearance. This method would also provide real-experience satisfaction for the user when he or she uses the virtual tour application. However, some weaknesses are evident in the use of this method, mainly forcing the researcher to first determine the image size and use that is suitable for preventing image blurring or reduced resolution when the image is zoomed in [30].

For the interface design development of the campus virtual tour, the researcher emphasises on the usability features of the application to achieve the best user experience. Therefore, a questionnaire was conducted for 10 sample virtual tours to examine the sample features that can be used for the application in this study. These usability features are based on the Heuristic List of Jacob Nielsen:

- Visibility of system status

- Match between system and the real world

- User control and freedom

- Consistency and standard

- Error prevention

- Recognition rather than recall

- Flexibility and efficiency of use

- Aesthetic and minimalist design

- Help users recognise, diagnose, and recover from error

- Help and documentation

The findings of this survey can be referred to in Table 2. Information regarding the features is collected and used as a guide throughout the process of designing the interface of the virtual tour application, so that the user could fully use this application and feel the real experience as if being in the actual location.

\subsection{FUTURE WORK}

Even though this study has achieved its main research objective, which is to investigate an effective interaction design to develop a campus virtual tour web application, some suggestions for future works are still required. One suggestion is to conduct a Cognitive Walkthrough assessment on the six participants to measure improvement in user interaction with the campus virtual tour web application in this study. This assessment is an assessment method to assess the system or application usability level besides enabling access to the diverse user interaction styles when browsing for information in the application. The results of this assessment would lead to the development of a real virtual tour web application that covers interaction style aspects and user needs and wants. Actual participants numbering 100 people in total could test this system to obtain user feedback of the system in terms of usability, effectiveness, and interaction.

\section{CONCLuSion}

The main objective of this study was to investigate an effective interaction design for developing a campus virtual tour web application that would allow the visitor to enjoy and appreciate the experience of being in a natural environment through the implementation of non-immersive technology. An interview was done with the staff of Tasik Chini Research Centre (TCRC) to obtain the user perspective regarding information display. The findings of the interview analysis were used as an input and guide to design the interface of the Tasik Chini virtual tour portal. 
The International Journal of Multimedia \& Its Applications (IJMA) Vol.10, No.1/2/3, June 2018

In addition, the analysis of related works also contributed towards the selection of a photorealistic-based panoramic technique, which was implemented in the development of the virtual tour portal, while simultaneously realising the objective of this study, which is to develop an interface design exploration model for the UKM virtual web application. In summary, the findings of this study have met all research objectives identified in the initial research phase.

\section{ACKNOWLEDGEMENTS}

This study was supported by the Top-Down Research Grant TD-2016-006, Universiti Kebangsaan Malaysia, Faculty of Technology and Information Science, Centre for Software Technology and Management, Multimedia Software and Research Group.

\section{REFERENCES}

[1] Maines C \& Tang S (2015) “An Application of Games Theory to Virtual University Campus Tour and Interior Navigation”, International Conference on Development of E-System Engineering (DeSE) 2015

[2] Gupta K, Shastry A, Krishmani D, M Sahu, Gupta G.P (2017) "Implementation of Hashing an Virtual Tour", The International Conference on Data Engineering and Communication Technology, pp.501510

[3] (1970) International Union for the Conservation Nature

[4] Palmer J.A (1998) Environmental Education in the 21st Century: Theory, Practice, Progress and Promise, Routledge, London

[5] Greenwald S, Kulik A, Kunert A, Beck S, Frohlich, Cobb S, Parsons S, Newbutt N et al (2017) "Technology and Application for Collaborative Learning in Virtual Reality", 12th International Conference on Computer Supported Collaborative Learning (CSCL), pp.719-726

[6] Weiler B \& Ham S (2001) "Tour Guides and Interpretation",The Encyclopedia of Ecotourism, pp.549-563

[7] Bos L, McCabe S \& Johnson S (2013) "Learning Never Goes on Holiday: An Exploration of Social Tourism as a Context for Experiential Learning",Current Issues in Tourism, pp.859-875

[8] Namsong S (2009) "Virtual Campus Tour",14th Annual Technology, Colleges, and Community Worldwide Online Conference

[9] Fominykh M, Prasolova-Forland E, Morozov M, Gerasimov A (2009) "Virtual Campus as a Framework for Educational and Social Activities",International Journal of Emerging Technologies in Learning

[10] Kybartaite A, Nousiainen J, Malmivuo J (2013) "Technology and Methods in Virtual Campus for Improving Learning Campus", Computer Application in Engineering Education 21:185

[11] Barringer E.R (2015) "A Mixed Methods Assessment of the Development, Use and Educational Effectiveness of University Campus Sustainability Tours",Master Theses \& Specialist Project Graduate School of Western Kentucky University

[12] Yuan L, Hong L, Chris C, Rukai C (2009) “An Exploration of Digital Tourism Design based on Virtual Reality"

[13] Wyk E \& Villiers R (2009) "Virtual Reality Training Application of Mining Industry", Proceedings of the 6th International Conference on Computer Graphics, Virtual Reality, Visualisation and Interaction in Africa

[14] Othman Ibrahim, Shahrul Azni Mohd Yusof, Ruzinoor Che Mat, Fadziana Faisal, Amlus Ibrahim, Abdul Nasir Zulkifli (2007) "Enhancing Virtual Tourism - Adoption and Implementation of Virtual Reality Techniques",Readings on tourism and hospitality, Universiti Utara Malaysia Press, Sintok, pp. $163-180$

[15] Szeliski R \& Shum H.Y (1997) “Creating Full View Panoramic Image Mosaic and Environment Maps", Proceeding on 24th Annual Conference on Computer Graphics and Interactive Technique, pp. 251-258

[16] Hookham G, Nesbitt K, Cooper J, Rasiah R (2014) "Developing a Virtual Tour of a Community Pharmacy for use in Education", Proceedings of IT in Industry, pp.33-37

[17] Hyung W.K, Soon H.p, Anjyo K, Sung Y.S (2001) "Tour into the Picture using a Vanishing Line and its Extension to Panoramic Images”,Computer Graphics Forum 2001 
The International Journal of Multimedia \& Its Applications (IJMA) Vol.10, No.1/2/3, June 2018

[18] Shum H.Y \& Kang S.B (2000) "Review of Image-Based Rendering Technique”,IEEE SPIE Visual Communication and Image Processing VCIP 213, pp.1-12

[19] Sweller J, Ayres P \& Kalyuga S (2013) "Cognitive Load Theory”, Springer-Verlag Berlin Heidelberg

[20] Norman D.A \& Draper S.W (1986) "User Centered System Design: New Perspective on HumanComputer Interaction", Lawrence Erlbaum Associates Publisher

[21] Baidu R (2016) "Basic Patterns for Mobile Navigation: A Primer",Available: https://www.nngroup.com/articles/mobile-navigation-patterns/

[22] Bennet K.B \& Flach J.M. "Display and Interface Design Subtle Science, Exact Art", 1st Edition. USA:CRC Press, Taylor \& Francis Group

[23] Normala Rahim, Tengku Siti Meriam Tengku Wook, Nor Azan Mat Zin (2011) "Developing Conceptual Model of Virtual Museum Environment based on User Interaction Issues"International Visual Informatics Conference

[24] Viana P, Chambel T, Bove V.M, Strover S, Thomas G (2016) "Guest Editorial: Immersive Media Experiences", Multimedia Tools and Application 75: 12285.

[25] Huang F \& Klette R (2009) "Stereo Panorama Acquisition and Automatic Image Disparity Adjustment for Stereoscopic Visualization",Multimedia Tools and Application 47:323.

[26] Fu Z \& Wang L (2014) "Optimized Design of Automatic Image Mosaic", Multimedia Tools and Application 72:503.

[27] Wang Z, Chen Y, Zhu Z, Zhao W (2016) "An Automatic Panoramic Image Mosaic Method based on Graph Model",Multimedia Tools and Application 75:2725.

[28] Kokate M.D, Wankhede V.A, Patil R.S (2017) "Survey: Image Mosaicing based on Feature Extraction",International Journal of Computer Applications 165:0975. doi: 10.5120/ijca2017913776

[29] Maponga R (2017) “Image Stitching Techniques”, Electrical and Computer Engineering Design Handbook

[30] Christopoulos D, Gaitatzes A, Papaioannou G (2003) "Image-Based Technique for Enhancing Virtual Reality Environments",2nd International Workshop on ICTs, Arts and Cultural Heritage

[31] Tengku Siti Meriam Tengku Wook, Hairulliza Mohd Judi, Noraidah Sahari @ Ashaari, Hazura Mohamed, Siti Fadzilah Mat Noor, Normala Rahim (2016) "Interaction Design Model in Virtual Museum Environment” Asia-Pacific Journal of Information Technology and Multimedia Vol. 5, No 1, June 2016: 71-81

[32] Saidatul A.Isyah Ahmad Shukri, Haslina Arshad, Rimaniza Zainal Abidin (2017) "The Design Guidelines of Mobile Augmented Reality for Tourism in Malaysia" 2nd International Conference on Applied Science and Technology 2017(ICAST 2017) Vol. 1891

[33] Meng Chun Lam, Haslina Arshad, Anton Satria Prabuwono, Siok Yee Tan, S. M.M. Kahaki (2017) "Interaction Techniques In Desktop Virtual Environment: The Study Of Visual Feedback And Precise Manipulation Method" Multimedia Tools and Application, pp.1-32

[34] Normala Rahim, Tengku Siti Meriam Tengku Wook, Nor Azan Mat Zin (2017) “Analysis on User Interaction in Virtual Heritage: Virtual Museum Environment" Indian Journal of Science and Technology, Vol. 10(48)

[35] Nazrita Ibrahim, Nazlena Mohamad Ali, Noor Faezah Mohd Yatim (2015) "Factors Facilitating Cultural Learning in Virtual Architectural Heritage Environment: End User Perspective" Journal on Computing and Cultural Heritage (JOCCH), Vol. 8 Issues 2

\section{AUTHORS}

Tengku Siti Meriam Tengku Wook received Bachelor Degree and Master in Information Technology from National University of Malaysia respectively in 1998 and 1999 and PhD in Software Engineering from University Malaya, Malaysia in year 2012. Currently, she is the programme coordinator for Multimedia System and also a member of Multimedia and Usability research group in Software Technology and Management Research Centre, Faculty of Information Science and Technology, National University of Malaysia. Her field of specialization are Human Computer Interaction that include multimedia application, user interaction design and usability, virtual and augmented reality and also elearning.

Noraidah Sahari @ Ashaari received degree BA Cum Lauda in year 1984 from SUNY at New Paltz, New York USA. In year 1987, she received MSc in Mathematics/Physics from West Virginia University, USA. She also got her Diploma in Education from University Technology Malaysia in 1988. She graduated in Doctor of Philosophy in Virtual Environment from University Putera Malaysia. Currently, she is the 
The International Journal of Multimedia \& Its Applications (IJMA) Vol.10, No.1/2/3, June 2018

Head of Software Technology and Management Research Centre, Faculty of Information Science and Technology, National University of Malaysia. She is also a part of Multimedia and Usability (MMU) and Industrial Computing (ICOMP) research group. Her field of specialization include empirical usability and information system evaluation, multimedia application and e-learning.

Mushrifah Idris received her Diploma in Science with Education and BSc in Environmental Science respectively from University Putra Malaysia, Serdang, Malaysia. She pursued her PhD on Environmental Toxicology at King's College, London, United Kingdom. She work as short term secondment to UNESCO, Paris from 1998 until 2000. From 2000 until 2001, she work as a full secondment to UNESCO, Paris. Currently, she works as a lecturer at National University of Malaysia and also as the Head of Tasik Chini Research Centre, one of the living lab in National University of Malaysia where the main research conducted is on lake and natural resources management, hyper accumulator in aquatic and terrestrial plant, and heavy metals in environment.

Nor Azan Mat Zin received B.Sc degree in Chemistry from Florida Institute of Technology, Melbourne, Florida, USA in 1983 and Dip. Ed in Physics and Chemistry from National University of Malaysia in year 1986. In year 1997, she received MEd in IT and Resources also from National University of Malaysia. She pursued her PhD in Information Science/Multimedia and graduated in 2005 from National University of Malaysia. Currently, she is the head of Multimedia \& Usability research group which ia a part of Software Technology and Management Research Center, Faculty of Information Science and Technology, National University of Malaysia. Her primary research interest is Advanced Technology for Learning

Hairulliza Mohamad Judi received her B.Sc and M.Sc respectively from National University of Malaysia, Bangi, Malaysia. Currently, she is a senior lecturer at Faculty of Information Science \& Technology, National University of Malaysia. She is a part of Industrial Computing (ICOMP) and Service Science (SS) research group which are in Software Technology and Management Research Centre (SOFTAM), Faculty of Information Science and Technology, National University of Malaysia. Her expertise are Simulation and Modelling and Quality Models.

Norleyza Jailani received her B.Sc in Computer Science from National University of Malaysia in 1992 and Master of Science in Computer Science (Computer Network \& Distributed System) from University College Dublin in 1995. She started her career as a lecturer at National University of Malaysia from 1996 until now. Currently, she is a part of Programming and Software Technology (ATUR) and Service Science (SS) research group which are in Software Technology and Management Research Centre (SOFTAM), Faculty of Information Science and Technology, National University of Malaysia. Her specialization are Computer System \& Network Technology, Agent Technology and Mobile Computing.

Intan Yusrina Zairon received her Bachelor Degree of Computer Science (Interactive Media) from University Technical Melaka, Malaysia in 2012 and Master of Information Technology (Multimedia System) from National University of Malaysia in 2017. Currently, she is the research assistant for this Virtual Campus Project. 